\title{
Resolution of Nucleotide Sugars and Oligosaccharides by Lectin Affinity Chromatography ${ }^{1}$
}

\author{
Diane A. Blake and Irwin J. Goldstein ${ }^{2}$ \\ Department of Biological Chemistry, The University of Michigan, Ann Arbor, Michigan 48109
}

Received June 28, 1979

\begin{abstract}
Bandeiraea simplicifolia I (BS I) isolectins, immobilized on Sepharose beads, specifically retarded low molecular weight ligands containing terminal $\alpha$-D-galactopyranosyl and 2acetamido-2-deoxy- $\alpha$-D-galactopyranosyl residues. A BS I lectin-Sepharose column has been used to perform very efficient separations of structurally homologous sugar nucleotides and oligosaccharides. For example, UDP-glucose and UDP-galactose (and the corresponding 2-acetamido-2-deoxy derivatives) were separated by as much as three column volumes by a BS I lectin-Sepharose column. This column has also been used to resolve the alditols of lactose $(\beta$-D-Galp-( $1 \rightarrow 4)$-D-Glc) and melibiose $(\alpha$-D-Galp- $(1 \rightarrow 6)$-D-Glc), to analyze the radiochemical purity of UDP-galactose and UDP- $N$-acetyl-D-galactosamine preparations, and to analyze the relative proportions of UDP- $N$-acetyl-D-glucosamine and UDP- $N$-acetyl-D-galactosamine in the UDP- $N$-acetyl-D-hexosamine pool isolated from cultured cells.
\end{abstract}

Resolution of structurally similar sugar nucleotides and oligosaccharides by standard chromatographic techniques has often proved difficult. For example, although it is possible to resolve epimeric UDP-glucose and UDP-galactose using a paper chromatographic system in which UDP-galactose migrates with an $R_{\mathrm{UDP}-\text { gluense }}$ value of 0.84 $(1,2)$, the components become diffuse and the nucleotide sugars begin to hydrolyze during the lengthy chromatography. Similarly, lactose $(\beta$-D-galactopyranosyl-( $1 \rightarrow 4)$ $D$-glucose) and melibiose ( $\alpha$-D-galactopyranosyl-(1 $\rightarrow 6$ )-D-glucose) may be resolved by thin-layer chromatography $(3,4)$ or paper chromatography (5), but their relative rates of migration do not allow clean separations. It is therefore difficult to judge the purity of a given nucleotide sugar or oligosaccharide by these methods.

${ }^{1}$ This study was supported by National Institutes of Health Grants AM 10171 and CA 20424 to Irwin J. Goldstein and by National Institutes of Health Fellowship F32 CA 06172 to Diane A. Blake.

${ }^{2}$ To whom correspondence should be addressed.
In this study, we have taken advantage of the specificity of Bandeiraea simplicifolia I (BS I) ${ }^{3}$ isolectins for $\alpha$-linked D-galactopyranosyl and 2-acetamido-2-deoxy-D-galactopyranosyl residues (6) to perform very efficient separations of UDP-glucose and UDP - galactose, UDP- $N$-acetyl-D - glucosamine and UDP- $N$-acetyl-D-galactosamine, and lactose and melibiose after reduction to lactitol and melibiitol, respectively. A specific isolectin (BS I- $\mathrm{B}_{4}$ ) of the above isolectin mixture, which binds terminal $\alpha$-D-galactopyranosyl residues but not 2-acetamido-2deoxy- $\alpha$-D-galactopyranosyl residues, was used to separate UDP- $N$-acetyl-D-galactosamine from UDP-galactose.

\section{METHODS}

UDP-D-[6- $\left.{ }^{3} \mathrm{H}\right]$ glucose, $3.7 \mathrm{Ci} / \mathrm{mmol}$, was purchased from Amersham Corporation,

${ }^{3}$ Abbreviations used: BS I, Bandeiraea simplicifolia I; PBS, phosphate-buffered saline; solvent A, ethanol: 2-butanone:4 M morpholinium tetraborate (7:2:3); solvent $B$, ethyl acetate:pyridine: $0.005 \mathrm{~m}$ boric acid (2:3:1); Gal, galactose; Glc, glucose. 
Arlington Heights, Illinois; sodium boro $\left[{ }^{3} \mathrm{H}\right]-$ hydride $142 \mathrm{mCi} / \mathrm{mmol}$, from New England Nuclear Corporation, Boston, Massachusetts. Radiolabeled samples of UDP-galactose, UDP- $N$-acetyl-D-galactosamine, and UDP$N$-acetyl-D-glucosamine were generously provided by New England Nuclear Corporation and ICN Pharmaceuticals, Inc., Irvine, California. CNBr-activated Sepharose $4 \mathrm{~B}$ was a product of Pharmacia, Inc., Piscataway, New Jersey; Whatman No. 1 and DE81 paper were purchased from Whatman Inc., Clifton, New Jersey. Triton X-100, 2,5diphenyloxazole, and the preblended dry flour 2a2o were from RPI Corporation, Elk Grove Village, Illinois. Melibiose and lactose were purchased from Pfansteihl I aboratories, Inc., Waukegon, Illinois, and the corresponding ${ }^{3} \mathrm{H}$-labeled alditols were prepared by the method of Conrad et al. (7) and purified by preparative paper chromatography.

The Bandeiraea simplicifolia I isolectins were prepared and fractionated into purified isolectins as described by Murphy and Goldstein (6) and coupled to Sepharose 4B by a method similar to that of Ross et al. (8). CNBr-activated Sepharose 4B (6.0 g) was processed according to the manufacturer's instructions, the isolectin mixture $(74.6 \mathrm{mg}$

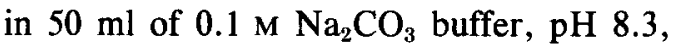
containing $0.5 \mathrm{M} \mathrm{NaCl}$ and $5 \mathrm{mg} / \mathrm{ml}$ methyl $\alpha$-D-galactopyranoside) was added, and the suspension was stirred gently for $2 \mathrm{~h}$ at room temperature. The lectin solution was filtered, $50 \mathrm{ml}$ of $1.0 \mathrm{M}$ ethanolamine in $0.5 \mathrm{M} \mathrm{NaCl}-$ $0.1 \mathrm{M} \mathrm{Na}_{2} \mathrm{CO}_{3}$ ( $\mathrm{pH}$ adjusted to 8.3) was added to the gel, and the suspension was stirred for an additional $2 \mathrm{~h}$ at room temperature. The lectin-gel was washed several times alternately with buffers at pH 6.0 and 8.0. The final product (BS I-Sepharose) contained approximately $3 \mathrm{mg}$ lectin $/ \mathrm{ml}$ of packed wet gel, as determined by absorbance readings at $280 \mathrm{~nm}$ of the original and filtered lectin solutions. The gel was packed into a $0.7 \times 26-\mathrm{cm}$ column, equilibrated in phos- phate-buffered saline (PBS) containing 0.15 $\mathrm{M} \mathrm{NaCl}, 0.1 \mathrm{M}$ phosphate buffer, $\mathrm{pH} 7.0$, $0.1 \mathrm{mM} \mathrm{CaCl}_{2}$, and $0.04 \% \mathrm{NaN}_{3}$, and stored at $4^{\circ} \mathrm{C}$. The BS $\mathrm{I}_{-} \mathrm{B}_{4}-$ Sepharose column $(1 \times 10.5 \mathrm{~cm})$ was prepared similarly. Both columns have been used routinely for more than 16 months with no loss of binding capacity. Neither UDP-glucose nor UDPgalactose showed any detectable differences in their interactions with unmodified Sepharose $4 \mathrm{~B}$ or $\mathrm{CNBr}$-activated Sepharose $4 \mathrm{~B}$ which had been subsequently reacted with ethanolamine.

Samples containing a mixture of the components to be separated (3-10 $\mathrm{nmol}$ of each) were dissolved in $0.5 \mathrm{ml} \mathrm{PBS}$ and applied to the BS I-Sepharose column. The column was eluted at a flow rate of 5-7 ml per hour and $1.1-\mathrm{ml}$ fractions were collected. All column separations were performed at $4^{\circ} \mathrm{C}$. Aliquots $(0.2 \mathrm{ml})$ of each column fraction were counted in a Packard Tri-Carb liquid scintillation spectrophotometer using a scintillation fluid containing $33 \%$ Triton $\mathrm{X}-100,67 \%$ toluene, and $4 \mathrm{~g}$ fluor $2 \mathrm{a} 2 \mathrm{o}$ per liter.

Paper chromatographic separations of UDP-galactose and UDP-glucose were performed as described by Carminatti et al. (2). Aliquots $(0.2 \mathrm{ml})$ from the peak of void volume and included radioactivity were spotted on $1 \times 23$-in. strips of Whatman No. 1 paper (EDTA treated) and chromatographed $50 \mathrm{~h}$ in solvent $A$ (ethanol:2butanone: $4 \mathrm{M}$ morpholinium tetraborate (7: 2:3)). Authentic UDP- $\left[{ }^{3} \mathrm{H}\right]$ glucose and UDP$\left[{ }^{14} \mathrm{C}\right]$ galactose were spotted on a separate strip of Whatman No. 1 paper and chromatographed along with the column fractions. Chromatographic identification of lactitol and melibiitol was performed on 1 $\times 23$-in. strips of borate-impregnated DE81 paper for $24 \mathrm{~h}$ in solvent $\mathrm{B}$ (ethyl acetate: pyridine:0.005 $\mathrm{M}$ boric acid $(2: 3: 1)(7))$. A $\left[{ }^{14} \mathrm{C}\right]$ galactose standard was included in the system so that $R_{\text {galactose }}$ values could be calculated. 


\section{RESULTS}

The elution profile of UDP- $\left[{ }^{3} \mathrm{H}\right]$ glucose and UDP- $\left[{ }^{14} \mathrm{C}\right]$ galactose from the BS ISepharose column is shown in Fig. 1. All of the ${ }^{3} \mathrm{H} \mathrm{cpm}$ and $3.9 \%$ of the ${ }^{14} \mathrm{C} \mathrm{cpm}$ were eluted in the void volume of the column. The major portion of the ${ }^{14} \mathrm{C} \mathrm{cpm}(95 \%)$ was retarded by the BS I-Sepharose column and eluted as a single, symmetrical peak. More than $95 \%$ of the total applied ${ }^{3} \mathrm{H}$ and ${ }^{14} \mathrm{C} \mathrm{cpm}$ were recovered. The UDP-glucose and UDP-galactose samples were separated by more than three column volumes by this procedure. The ${ }^{14} \mathrm{C} \mathrm{cpm}$ that coeluted with UDP- $\left[{ }^{3} \mathrm{H}\right]$ glucose could be a result of either column overloading or contamination of the UDP- $\left[{ }^{14} \mathrm{C}\right]$ galactose with UDP- $\left[{ }^{14} \mathrm{C}\right]$ glucose. In order to differentiate between these two possibilities, peak fractions from the void volume and included radioactivity were subjected to paper chromatographic analysis in solvent system A, which is capable of resolving UDP-glucose and UDP-galactose (2).

As shown in Fig. $2 \mathrm{~A}$, the ${ }^{14} \mathrm{C} \mathrm{cpm}$ that eluted in the void volume of the BS I-Sepharose column cochromatographed on paper with UDP- $\left[{ }^{3} \mathrm{H}\right]$ glucose. The ${ }^{14} \mathrm{C} \mathrm{cpm}$ that were retarded by the isolectin column migrated more slowly than UDP-glucose in this paper system and with the mobility

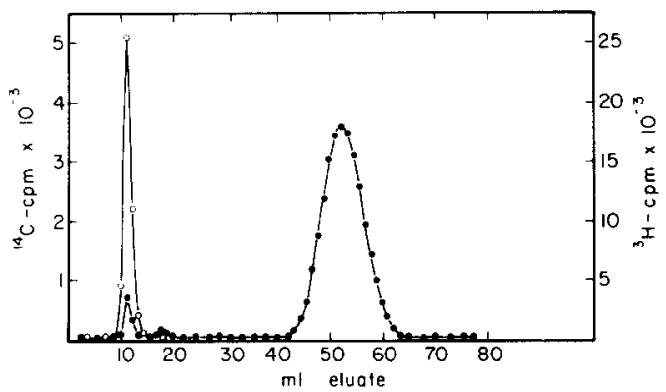

Fig. 1. Separation of UDP- $\left[{ }^{3} \mathrm{H}\right]$ glucose and UDP$\left[{ }^{14} \mathrm{C}\right]$ galactose on BS I-Sepharose. UDP- $\left[{ }^{3} \mathrm{H}\right]$ glucose (2 $\mu \mathrm{Ci}, 3.7 \mathrm{Ci} / \mathrm{mmol})$ and UDP-[ ${ }^{14} \mathrm{C}$ ]galactose $(0.2$ $\mu \mathrm{Ci}, 301 \mathrm{mCi} / \mathrm{mmol}$ ) were dissolved in PBS and applied to the BS I-Sepharose column. The column was eluted at a flow rate of $7 \mathrm{ml} / \mathrm{h}$ with PBS and $1.1-\mathrm{ml}$ fractions were collected. (O) ${ }^{3} \mathrm{H} \mathrm{cpm} ;(\bullet){ }^{14} \mathrm{C} \mathrm{cpm}$.

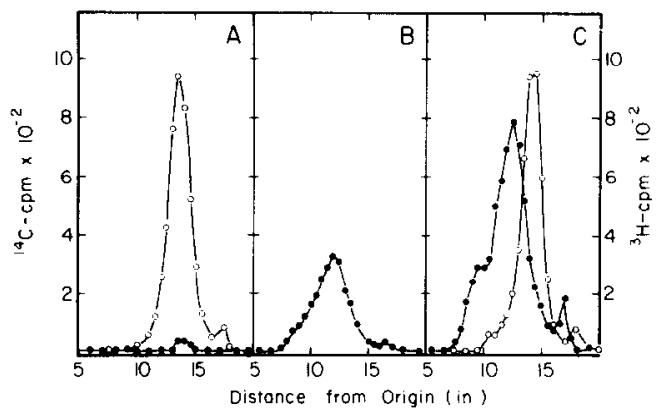

FIG. 2. Paper chromatography of fractions from BS I-Sepharose column separation of UDP- $\left[{ }^{3} \mathrm{H}\right]$ glucose and UDP- $\left[{ }^{14} \mathrm{C}\right]$ galactose. Aliquots $(200 \mu \mathrm{l})$ from the peak of void volume (panel A) and included radioactivity (panel B) were spotted on Whatman No. 1 paper and chromatographed as described under Methods. Authentic UDP- $\left[{ }^{3} \mathrm{H}\right]$ glucose and UDP- $\left[{ }^{14} \mathrm{C}\right]$ galactose (panel C) were spotted on a separate strip and chromatographed with the column fractions. $(\mathrm{O}){ }^{3} \mathrm{H} \mathrm{cpm}$; (•) ${ }^{14} \mathrm{C}$ cpm.

expected for UDP-galactose (Fig. 2B). Figure $2 \mathrm{C}$ shows the separation of standard UDP. $\left[{ }^{14} \mathrm{C}\right]$ galactose and UDP- $\left[{ }^{3} \mathrm{H}\right]$ glucose in this solvent system. On the basis of these data, we have identified the ${ }^{14} \mathrm{C}$ contaminant that elutes in the void volume of the BS I-Sepharose column as UDP- $\left[{ }^{14} \mathrm{C}\right]$ glucose. This conclusion is substantiated by the fact that small amounts of $\left[{ }^{4} \mathrm{C}\right]$ glucose have been detected in acid hydrolysates of this UDP- $\left[{ }^{14} \mathrm{C}\right]$ galactose preparation (New England Nuclear data sheet for UDP- $\left[{ }^{14} \mathrm{C}\right]$ galactose, Lot 1025-035).

The isolectin mixture covalently coupled to Sepharose 4B contains " $A$ " subunits which bind 2-acetamido-2-deoxy- $\alpha$-D-galactopyranosyl residues. Thus, the column should also have the capacity to resolve UDP- $N$-acetyl-D-glucosamine and UDP- $N$ acetyl-D-galactosamine, two nucleotide sugars which are very difficult to separate by conventional techniques. To test this possibility, a mixture of UDP- $N$-acetyl-D- $\left[{ }^{3} \mathrm{H}\right]-$ glucosamine and UDP- $N$-acetyl-D- $\left[{ }^{14} \mathrm{C}\right]$ galactosamine was applied to the BS I-Sepharose column. The elution profile (Fig. 3) is quite similar to that obtained with mixtures of UDP-glucose and UDP-galactose. UDP$\mathrm{N}$-acetyl-D-glucosamine did not interact 


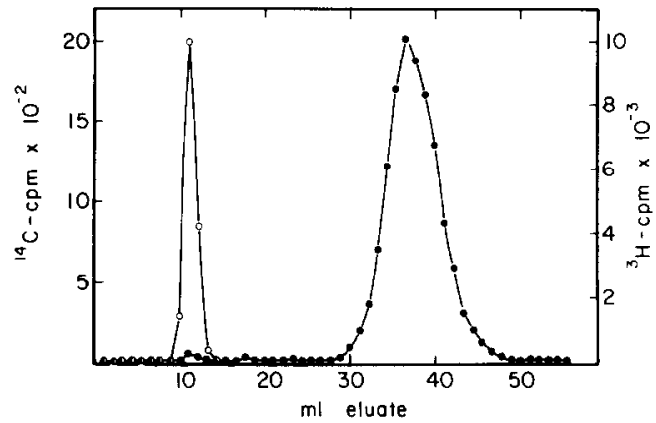

FIG. 3. Separation of UDP- $N$-acetyl-D- $\left[{ }^{3} \mathrm{H}\right]$ glucosamine and UDP- $N$-acetyl-D- $\left[{ }^{14} \mathrm{C}\right]$ galactosamine on BS I-Sepharose. UDP- $N$-acetyl-D- $\left[{ }^{3} \mathrm{H}\right]$ glucosamine $(0.2$ $\mu \mathrm{Ci}, 6.6 \mathrm{Ci} / \mathrm{mmol})$ and UDP- $N$-acetyl-D- $\left[{ }^{14} \mathrm{C}\right]$ galactosamine $(0.2 \mu \mathrm{Ci}, 47.2 \mathrm{mCi} / \mathrm{mmol})$ were dissolved in $0.5 \mathrm{ml} \mathrm{PBS}$ and applied to the BS I-Sepharose column. The column was eluted at a flow rate of $6.0 \mathrm{~m} / \mathrm{h}$ with PBS 1.1-ml fractions were collected. $(O)^{3} \mathrm{H} \mathrm{cpm}$; (๑) ${ }^{14} \mathrm{C} \mathrm{cpm}$.

with the column material and was eluted in the void volume; UDP- $N$-acetyl-D-galactosamine was retarded and was eluted approximately two column volumes later. A small amount of contaminating ${ }^{14} \mathrm{C}$-labeled material was eluted before the major peak of UDP- $N$-acetyl-D-[ $\left[{ }^{14} \mathrm{C}\right]$ galactosamine; this material was not identified.

Using the BS I-Sepharose column described here, we have analyzed a number of radiolabeled UDP-galactose and UDP- $N$ acetyl-D-galactosamine samples for radio- chemical purity. The results are shown in Table 1. In most cases, we were able to detect somewhat larger amounts of impurities than had been reported by the manufacturers. The lectin-Sepharose column was often capable of resolving the radiolabeled UDPgalactose into three or four components. The radioactivity which eluted in the void volume was identified in all samples as UDP-glucose by paper chromatography. Peaks 1 and 2 were retarded slightly by the BS I-Sepharose column and were presumed to be breakdown products of UDP-galactose, possibly free D-galactose and D-galactose 1-phosphate. Because of the small quantities of peaks 1 and 2 present in most samples, these components were not identified. However, passage of UDP-galactose through the BS I column was not in itself responsible for the breakdown into peaks 1 and 2, inasmuch as column-purified UDP-[ $\left.{ }^{14} \mathrm{C}\right]$ galactose could be rechromatographed to yield a single peak identified as UDP- $\left[{ }^{14} \mathrm{C}\right]$ galactose by paper chromatography (data not shown). Radiolabeled UDP- $N$-acetyl-D-galactosamine was also analyzed by BS I-Sepharose column chromatography and shown to be of high radiochemical purity (see Table 1).

A further application of this lectin affinity column can be demonstrated in the study of the metabolic pools of cultured cells.

TABLE 1

Analysis of Radiolabeled UDP-Galactose and UDP-N-ACFtyi-d-Galactosamine Samples

\begin{tabular}{|c|c|c|c|c|c|c|}
\hline \multirow[b]{2}{*}{ Sample } & \multirow[b]{2}{*}{ Catalog and lot No. } & \multicolumn{4}{|c|}{ Percentage of total radioactivity present } & \multirow{2}{*}{$\begin{array}{l}\text { Reported } \\
\text { purity }\end{array}$} \\
\hline & & UDP-glucose & Peak 1 & Peak 2 & UDP-Gal & \\
\hline \multirow[t]{6}{*}{ UDP-galactose } & NEC-429 Lot $1025-035$ & 3.9 & 1.1 & - & 95 & $>99.2$ \\
\hline & NEC-429 Lot $1060-049$ & 0.3 & 0.7 & - & 99 & $>99.5$ \\
\hline & NEC-429 Lot $1025-288$ & - & 0.4 & - & 99.6 & $>99.6$ \\
\hline & NET-213 Lot 1082-111 & 3.2 & 3.7 & 2.1 & 91 & $>97$ \\
\hline & ICN 13062 Lot 186272 & - & 8.2 & - & 91.2 & $>99$ \\
\hline & & Void volume & Peak 1 & Peak 2 & UDP-GalNAc & \\
\hline \multirow{2}{*}{$\begin{array}{l}\text { UDP- } N \text {-acetyl-D- } \\
\text { galactosamine }\end{array}$} & NEC-529 Lot 809-035 & 0.9 & 0.7 & - & 98.4 & $>99$ \\
\hline & NET-465 Lot $919-070$ & 1.4 & - & - & 98.6 & $>99$ \\
\hline
\end{tabular}


Primary cultures of chick embryo chondrocytes were incubated in the presence of $\mathrm{D}-\left[{ }^{14} \mathrm{C}\right]$ glucosamine and the UDP- $N$-acetyl$\mathrm{D}-\left[{ }^{14} \mathrm{C}\right]$ hexosamine pool was isolated by preparative paper chromatography (9). The relative proportions of UDP- $N$-acetyl-Dglucosamine and UDP- $N$-acetyl-D-galactosamine in this pool sample were analyzed by chromatography on BS I-Sepharose as shown in Fig. 4. The ratio of UDP-N-acetylD-glucosamine to UDP- $N$-acetyl-D-galactosamine in this sample was $3.3: 1$, which agrees well with the values of $2.9: 1$ and $3.0: 1$ obtained by other more time-consuming methods $(9,10)$.

The resolution of structurally related oligosaccharides has often proved as difficult as the separation of sugar nucleotides. In this study, we have used the BS I-Sepharose column to separate the alditols of lactose $(\beta$-D-Galp- $(1 \rightarrow 4)-\mathrm{D}-\mathrm{Glc})$ and melibiose $(\alpha-$ $\mathrm{D}-\mathrm{Gal} p-(1 \rightarrow 6)-\mathrm{D}-\mathrm{Glc})$. The parent oligosaccharides were reduced with $\mathrm{NaB}^{3} \mathrm{H}_{4}$ to facili-

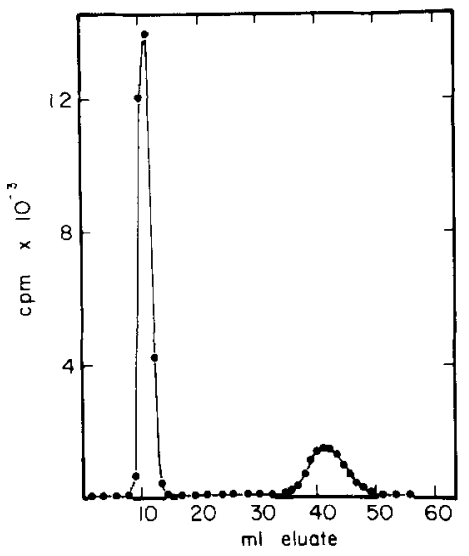

FIG. 4. Determination of relative proportions of UDP- $N$-acetyl-D-glucosamine and UDP- $N$-acetyl-Dgalactosamine in the UDP- $N$-acetyl-D-hexosamine pool of cultured chick embryo chondrocytes. The UDP- $N$ acetyl-D-hexasamine pool was isolated as described in reference 9, dissolved in $0.5 \mathrm{ml} \mathrm{PBS}$, and applied to the BS I-Sepharose column. The ratio of UDP- $N$ acetyl-D-glucosamine to UDP- $N$-acetyl-D-galactosamine in the pool sample was calculated by quantitating the $\mathrm{cpm}$ in the void volume (UDP- $N$-acetyl-D-glucosamine) and included (UDP- $N$-acetyl-D-galactosamine) peaks.

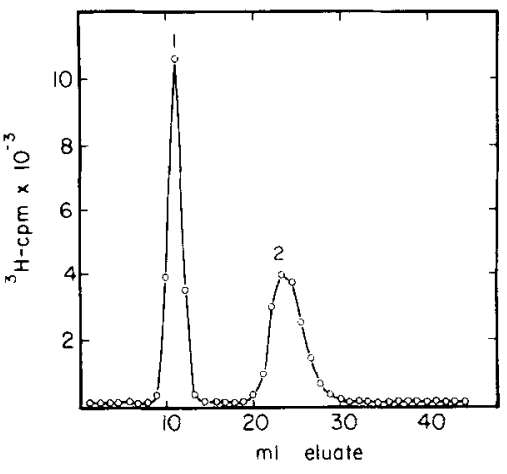

FIG. 5. Separation of $\left[{ }^{3} \mathrm{H}\right]$ lactitol and $\left[{ }^{3} \mathrm{H}\right]$ melibiitol on BS I-Sepharose. Ten nanomoles each of $\left[{ }^{3} \mathrm{H}\right]$ lactitol and $\left[{ }^{3} \mathrm{H}\right]$ melibiitol, prepared as described under Methods, were disolved in $0.25 \mathrm{ml}$ PBS and applied to the BS I-Sepharose column. The column was eluted with PBS at a flow rate of $5 \mathrm{ml} / \mathrm{h}$ and $1.1-\mathrm{ml}$ fractions were collected. (O) ${ }^{3} \mathrm{H} \mathrm{cpm}$.

tate their detection and subsequent identification by paper chromatography. The elution profile of a mixture of $\left[{ }^{3} \mathrm{H}\right]$ lactitol and $\left[{ }^{3} \mathrm{H}\right]-$ melibiitol on the lectin-Sepharose column is depicted in Fig. 5. The first component (peak 1) elutes in the void volume, as expected for lactitol; the second component (peak 2) is retarded by the BS I-Sepharose column inasmuch as melibiitol contains a terminal $\alpha$-D-galactopyranosyl residue. Peaks 1 and 2 were further identified as lactitol and melibiitol by paper chromatography as shown in Fig. 6. Standard $\left[{ }^{3} \mathrm{H}\right]$ lactitol (panel A) and peak 1 (panel B) migrated with $R_{\text {galactose }}$ values of 0.55 and 0.52 , respectively, in a paper chromatographic system (solvent B) which resolves lactitol and melibiitol. Standard $\left[{ }^{3} \mathrm{H}\right]$ melibiitol (panel $\mathrm{C}$ ) and peak 2 (panel D) chromatographed with $R_{\text {galactose }}$ values of 0.36 and 0.40 , respectively, in the same solvent system. Thus the BS I-Sepharose column is capable of retarding oligosaccharides that contain a nonreducing terminal $\alpha$-D-galactopyranosyl residue and, presumably, should also retard oligosaccharides containing terminal 2-acetamido-2-deoxy$\alpha$-D-galactopyranosyl residues.

In a final series of experiments, a second lectin column was prepared using the purified $\mathrm{B}_{4}$ component of the BS I isolectin mixture. 


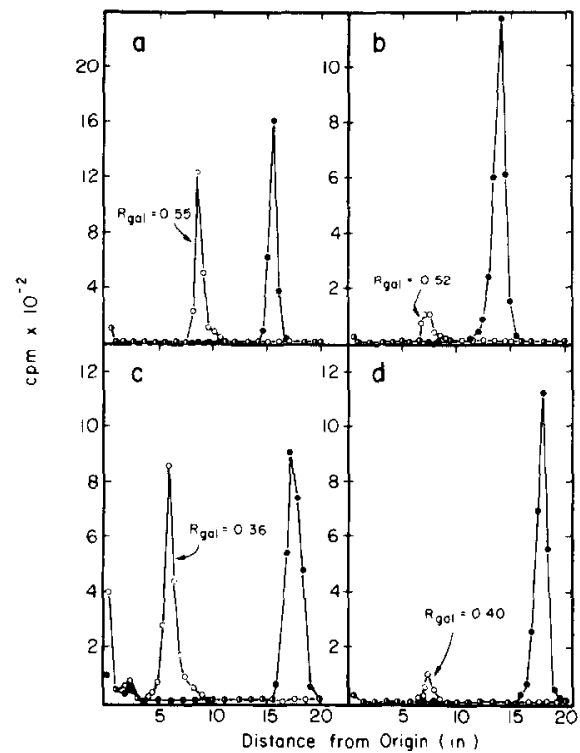

FIG. 6. Paper chromatographic identification of peaks from column scparations of lactitol and melibiitol. Aliquots of standard $\left[{ }^{3} \mathrm{H}\right]$ lactitol (panel A), peak 1 from the BS I-Sepharose column (panel B), standard $\left[{ }^{3} \mathrm{H}\right]$ melibiitol (panel C), and peak 2 from the affinity column (panel D) were spotted on borate-treated DE81 paper and chromatographed as described under Methods. A [ $\left.{ }^{14} \mathrm{C}\right]$ galactose standard was included in the system to permit calculation of $R_{\text {galactose }}$ values for each ${ }^{3} \mathrm{H}$-labeled sample. (O) ${ }^{3} \mathrm{H} \mathrm{cpm} ;(0){ }^{14} \mathrm{C} \mathrm{cpm}$.

This isolectin (BS I-B $_{4}$ binds terminal $\alpha$-Dgalactopyranosyl residues but not the corresponding 2-acetamido-2-deoxy derivative. The BS I-B $\mathrm{B}_{4}$ column was employed to separate a mixture of UDP- $N$-acetyl-D- $\left[{ }^{3} \mathrm{H}\right]$ galactosamine and UDP- $\left[{ }^{14} \mathrm{C}\right]$ galactose, as shown in Fig. 7. From the elution profile, it appears that the UDP- $N$-acetyl-D-galactosamine may have been slightly retarded by the $\mathrm{BS}$ I- $\mathrm{B}_{4}$ Sepharose column, although this retardation did not affect the resolution of the two sugar nucleotides. This very weak interaction of UDP- $N$-acetyl-D-galactosamine with the isolectin column reflects the low association constant of BS I-B $_{4}$ for 2-acetamido-2-deoxy$\alpha$-D-galactopyranosyl residues $\left(2 \times 10^{2}\right.$ liter $\mathrm{mol}^{-1}$ ) (unpublished data).

\section{DISCUSSION}

The results presented here demonstrate that the BS I-Sepharose column is a very effective affinity adsorbent for low molecular weight ligands containing terminal $\alpha$-Dgalactopyranosyl and 2-acetamido-2-deoxy$\alpha$-D-galactopyranosyl units. We have previously demonstrated (8) that the BS I isolectins, immobilized on Sepharose 4B, strongly bind multivalent glycoconjugates containing terminal $\alpha$-D-galactosyl and the corresponding 2-acetamido-2-deoxy derivatives, and that these glycoconjugates may be eluted from the BS I-Sepharose column by the competitive hapten, methyl $\alpha$-D-galactopyranoside. In this study, we found that monovalent ligands, such as nucleotide sugars and linear oligosaccharides, although not bound, are retarded by the BS I-Sepharose column. Such retardation allows separations without the addition of sugar haptens and eliminates the necessity for subsequent removal of low molecular weight sugars.

When low molecular weight ligands are to be separated, care must be taken to avoid overloading the affinity column. Since the lectin may bind, at saturation, $4 \mathrm{~mol}$ of ligand per mole of protein (11), the theoretical capacity of this column is approximately $2 \mu \mathrm{mol}(74.5 \mathrm{mg}$ lectin $/ 114,000 \mathrm{~g}$ lectin per

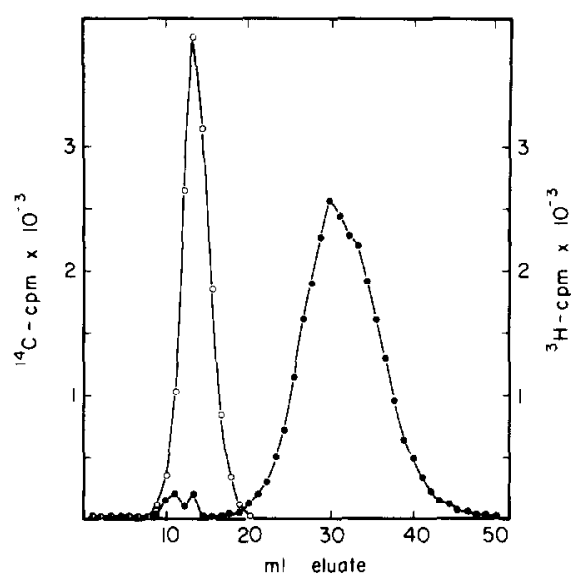

FIG. 7. Separation of UDP- $N$-acetyl-D- $\left[{ }^{3} \mathrm{H}\right]$ galactosamine and UDP- $\left[{ }^{14} \mathrm{C}\right]$ galactose on BS I-B ${ }_{4}-$ Sepharose. UDP- $N$-acetyl-D- $\left[{ }^{3} \mathrm{H}\right]$ galactosamine $(0.2 \mu \mathrm{Ci}, 13 \mathrm{Ci} /$ mmol) and UDP. $\left[{ }^{14} \mathrm{C}\right]$ galactose $(0.2 \mu \mathrm{Ci}, 301 \mathrm{mCi} / \mathrm{mmol})$ were dissolved in $0.5 \mathrm{ml} \mathrm{PBS}$ and applied to the BS $I_{-}-B_{4}-$ Sepharose column. The column was eluted at a flow rate of $5 \mathrm{ml} / \mathrm{h}$ with PBS and 1.1-ml fractions were collected. (O) ${ }^{3} \mathrm{H} \mathrm{cpm}$; (O) ${ }^{14} \mathrm{C} \mathrm{cpm}$. 
mole $\times 4$ binding sites per molecule). In practice, we have determined that the maximum capacity for the BS I-Sepharose column described here $(0.7 \times 26 \mathrm{~cm})$ is 0.2 $\mu \mathrm{mol}$. Due to its size and capacity, this column is suitable for analytical rather than preparative purposes. Larger columns could be utilized for preparative isolations of monovalent ligands.

We have used this lectin column to quantitate the purity of commercial radiolabeled UDP-galactose and UDP- $N$-acetyl-D-galactosamine samples, to determine the relative proportions of UDP- $N$-acetyl-D-glucosamine and UDP- $N$-acetyl-D-galactosamine in the pool of UDP- $N$-acetyl-D-hexosamine isolated from cultured cells, and to separate the structurally related disaccharides lactitol and melibiitol. Preliminary experiments in this laboratory have indicated that the column may also be used to separate reactants from products in a fixed time assay of UDP-galactose-4-epimerase activity. Although the spectrophotometric coupled enzyme assays presently available $(12,13)$ are more rapidly performed, they are only able to monitor the formation of UDP-glucose from UDP-galactose. A fixed time assay with subsequent separation of reactants and products on a BS I-Sepharose column would have an advantage in its ability to measure both the forward and reverse epimerase reaction; that is, to measure the formation of UDP-glucose from UDP-galactose or the formation of UDP-galactose from UDPglucose.
It is apparent that the BS I-Sepharose column has a wide range of applications and that it may be a valuable tool in many investigations involving the separation and quantitation of specific oligosaccharides and sugar nucleotides.

\section{ACKNOWLEDGMENTS}

We thank Drs. H. E. Conrad and Jung Ja Kim of the Department of Biochemistry, University of Illinois, Urbana, Illinois, for providing the UDP- $N$-acetyl-Dhexosamine pool sample. Mr. Barry Peters and Mr. Elliott Sumers of this laboratory prepared the BS $\mathrm{I}^{-} \mathrm{B}_{4}-$ Sepharose column, and Mr. Timothy Ross conducted some preliminary experiments in this system.

\section{REFERENCES}

1. Harrap, F. E. G. (1958) Nature 182, 876-878.

2. Carminatti, H., Passeron, S., Dankert, M., and Recondo, E. (1965) J. Chromatogr. 18, 342-348.

3. Hansen, S. A. (1975) J. Chromatogr. 105, 388-390.

4. Hansen, S. A. (1975) J. Chromatogr. 107, 224-226.

5. Kowkabany, K. (1954) Advan. Carbohyd. Chem. 9, 303-353.

6. Murphy, L. A., and Goldstein, I. J. (1977) J. Biol. Chem. 252, 4739-4742.

7. Conrad, H. E., Varboncoeur, E., and James, M. E. (1973) Anal. Biochem. 51, 486-500.

8. Ross, T. T., Hayes, C. E., and Goldstein, I. J. (1976) Carbohyd. Res. 47, 91-97.

9. Kim, J. J., and Conrad, H. E. (1974) J. Biol. Chem. 249, 3091-3097.

10. Bekesi, J. G., and Winzler, R. J. (1969) J. Biol. Chem. 244, 5663-5668.

11. Hayes, C. E., and Goldstein, I. J. (1975) J. Biol. Chem. 250, 6837-6840.

12. Beutler, E. (1975) Red Cell Metabolism, 2nd ed., pp. 97-102, Grune and Stratton, New York.

13. Tsai, C. M., Holmberg, N., and Ebner, K. E. (1970) Arch. Biochem. Biophys. 136, 233-244. 